\title{
AS REPRESENTAÇÕES SOCIAIS DAS MÃES ADOLESCENTES ACERCA DA EDUCAÇÃO ${ }^{1}$
}

\author{
TEENAGE MOTHERS' SOCIAL REPRESENTATION ABOUT \\ EDUCATION
}

\section{LAS REPRESENTACIONES SOCIALES DE LAS MADRES ADOLESCENTES ACERCA DE LA EDUCACIÓN}

\author{
Maria Angelica Silveira Padilha* \\ Alvaro Moreira Hypolito ** \\ Marilu Correa SoARes ${ }^{* * *}$ \\ Maria Emilia Nunes Bueno ${ }^{* * * *}$ \\ Ana CANDida Lopes Correa ${ }^{* * * * *}$ \\ Sonia Maria KönZGen MeINCKe ${ }^{* * * * *}$
}

\section{RESUMO}

Objetivo: Apreender as representações sociais das mães adolescentes acerca da educação. Método: Pesquisa qualitativa que utilizou a técnica de grupo focal para coleta dos dados, que foram submetidos à análise temática ancorada na Teoria das Representações Sociais. Resultados: Os hallazgos apontaram que as mães adolescentes representaram a sua trajetória escolar com dificuldades intelectuais ao longo dos anos escolares e os sintomas da gravidez dificultaram a permanência na escola. Assinalaram que a educação proporciona melhores condições de vida, de emprego e consumo de produtos mais caros para seus filhos. Apontaram a falta de políticas públicas que viabilizassem a permanência das mesmas no sistema educacional. Conclusão: A enfermagem poderá desempenhar um papel social relevante ao participar na construção de políticas públicas que incentivem a permanência e/ou retorno das mães adolescentes à escola, como forma de garantir a inserção social dessa parcelada população, evitando ciclo de baixa escolaridade e condições socioeconômicas desfavoráveis na vida das jovens brasileiras.

Palavras chave: Escolaridade, gravidez na adolescência, Enfermagem.

\footnotetext{
${ }^{1}$ Recorte de Dissertação de Mestrado "As Representações Sociais da Evasão Escolar para Mães Adolescentes: Contribuição para a Enfermagem”, apresentada ao Programa de Pós- Graduação de Enfermagem da Facultade de Enfermagem da Universidades Federal de Pelotas.

*Enfermeira.Mestranda do Programa de Pós-Graduação em Enfermagem da Faculdade de Enfermagem da Universidade Federal de Pelotas (UFPel). E-mail: mangellpadilha@hotmail.com

${ }^{* *}$ Pedagogo. Docente da Faculdade de Educação e do Programa de Pós-Graduação em Educação e do Programa de Pós-Graduação em Enfermagem da UFPel. E-mail: alvaro.hypolito@gmail.com

${ }^{* * *}$ Enfermeira Obstetra. Professora Faculdade de Enfermagem e do Programa de Pós-Graduação em Enfermagem da UFPel. E-mail: enfmari@uol.com.br

${ }^{* * * *}$ Enfermeira. Doutoranda do Programa Pós-Graduação em Enfermagem da Universidade Federal do Rio Grande, Brasil. E-mail: me_bueno@yahoo.com.br

${ }^{* * * * *}$ Enfermeira. Mestranda do Programa de Pós-Graduação em Enfermagem da Faculdade de Enfermagem da Universidade Federal de Pelotas, RS. Membro do Núcleo de Estudos em Práticas de Saúde e Enfermagem (NEPEn). Email: analopescorrea@hotmail.com

${ }_{* * * * * *}$ Enfermeira. Professora Faculdade de Enfermagem da Universidade Federal de Pelotas-RS. Brasil. Líder do Núcleo de Estudos em Práticas de Saúde e Enfermagem (NEPEn).E-mail: meinckesmk@gmail.com
} 


\begin{abstract}
Objective: This study aimed at understanding the social representations of teenage mothers about education. Method: A qualitative research was used, along with the Focus Group Technique to collect data that were submitted to thematic analysis, based on the Social Representation Theory. Results: The results showed that the teenage mothers described their school history as a period with intellectual difficulties, and the symptoms of pregnancy made it hard to stay in school. The young mothers emphasized that education provides better conditions of life, employment and consumption of expensive products for their children, and pointed out the lack of public policies to allow them to be in school. Conclusion: Nursing can perform a relevant social role in building public policies to motivate these adolescents to stay in and/or go back to school, as a way to guarantee their insertion in the society, avoiding low education and unfavorable social-economic conditions in their life.
\end{abstract}

Key words: Educational status, pregnancy in adolescence, Nursing.

\title{
RESUMEN
}

Objetivo: Comprender las representaciones sociales de las madres adolescentes acerca de la educación. Material y método: Investigación cualitativa que utilizó la técnica de grupo focal para la recolección de datos que fueron sometidos a análisis temático basada en la Teoría de las Representaciones Sociales. Resultados: Los resultados mostraron que las madres adolescentes describieron su trayectoria escolar como un período con dificultades intelectuales y que los síntomas del embarazo dificultaron su permanencia en la escuela. Señalaron que la educación proporciona mejores condiciones de vida, de empleo y aumento de consumo de productos más caros para sus hijos. Apuntaron la falta de políticas públicas que viabilicen sus permanencias en el sistema educacional. Conclusión: La enfermería podrá desempeñar un papel social relevante al participar en la construcción de políticas públicas que incentiven la permanencia y/o el retorno de las madres adolescentes a la escuela como forma de garantizar la inserción social de ese grupo de la población, evitando el ciclo de baja escolaridad, condiciones socioeconómicas desfavorables en la vida de las jóvenes brasileñas.

Palabras clave: Escolaridad, embarazo en la adolescencia, Enfermería.

Fecha recepción: 05/08/13. Fecha aceptación: 19/08/14.

\section{INTRODUÇÃO}

$\mathrm{Na}$ adolescência a gravidez tem sido tratada, nas últimas décadas, como um importante assunto de saúde pública, devido à amplitude desse fenômeno em todo o mundo. Uma gravidez, nessa fase, proporciona entrada precoce na vida adulta e um amadurecimento que adolescentes ainda não se encontram preparadas para enfrentar (1).

A gravidez na adolescência ainda é frequente nas jovens com pouca escolaridade e situação socioeconômica desfavorável. A baixa escolaridade é um fator predisponente para perpetuar a pobreza e desvantagens sociais e econômicas (2).

Dessa forma, acredita-se na importância da educação como fator de inclusão social, uma vez que isso se torna mais relevante quando relacionamos gravidez na adolescência e evasão escolar. Assim, a educação é o primeiro passo para romper o círculo vicioso da pobreza (1). A educação básica garante a todos os brasileiros a formação imprescindível para o exercício da cidadania e fornece os recursos para avançar no trabalho e em estudos posteriores.

Assim, buscou-se compreender um dos problemas de saúde pública que influencia 
não somente a vida dessas jovens, como também repercute na sociedade. Como embasamento teórico para construção do presente estudo, utilizou-se a Teoria das Representações Sociais (3). No campo das representações sociais, observa-se um interesse cada vez maior pela área da saúde que agrega estudos com adolescente relacionados à sexualidade e às Doenças sexualmente transmissíveis (DST) (4).

Entende-se que a representação social fornece subsídios para os julgamentos e as atitudes dando significado e coerência ao universo vivido, desde que seja elaborada de forma coletiva e a partir das trocas e práticas de um contexto histórico (3). De acordo com exposto, as adolescentes, ao representarem a gravidez na adolescência, associam-na a um sistema de pensamento social preexistente.

Estudos demonstram que as mães das adolescentes possuem, em sua maioria, baixa escolaridade, pois abandonam seus estudos para cuidar dos filhos e, muitas vezes, trabalham para garantir a subsistência familiar. Dessa forma, pelo baixo índice de educação só conseguem ocupações com menores ganhos, conseqüentemente, suas filhas, adolescentes, provavelmente serão futuras mães trabalhadoras, reproduzindo este círculo vicioso da pobreza por inter-gerações (5).

Vale ressaltar que prevalece em nossa cultura a representação da maternidade como algo positivo e socialmente valorizado para as mulheres (5). Assim, corrobora estudo (3) que ao buscar conhecer as representações acerca da gravidez na adolescência, identificou que as adolescentes elaboraram suas representações sobre a gravidez na adolescência a partir de seu contexto social.

Apesar da importância da temática poucos estudos relacionados com a Enfermagem, gravidez na adolescência e evasão escolar têm sido produzidos. Acredita-se que pesquisas nesta linha possibilitariam identificar a visão social da gravidez na adolescência e o impacto da ausência destas jovens na escola e, consequentemente, a construção de ações de apoio a esta população específica. Portanto, este artigo teve como objetivo apreender as representações sociais das mães adolescentes acerca da educação.

\section{MÉTODO}

A pesquisa teve abordagem qualitativa (6) exploratória e descritiva. Os sujeitos do estudo foram cinco mães adolescentes que preencheram os critérios de inclusão: participar da pesquisa Redes de Apoio à Paternidade na Adolescência (RAPAD) ${ }^{2}$; residir no perímetro urbano do Município de Pelotas/RS; ter abandonado a escola devido à gravidez. A pesquisa RAPAD, além de focar na paternidade, também teve como objetivo a caracterização das mães adolescentes. Desta forma, a seleção das respondentes do presente estudo deu-se a partir dessa pesquisa, o que facilitou o engajamento das mesmas devido ao vínculo que já havia se estabelecido entre os pesquisadores e as mães adolescentes.

$\mathrm{Na}$ coleta dos dados utilizou-se a técnica de grupo focal ${ }^{3}$, em dois encontros, com uma duração média de 3 horas e com intervalo de 6 dias entre eles. Foi realizado contato telefônico com 54 mães adolescentes identificadas no banco de dados da pesquisa RAPAD e que preenchiam os critérios do estudo, e apenas 13 aceitaram participar. A pesquisadora visitou pessoalmente as 13 mães adolescentes, explicou a pesquisa e forneceu vale- transporte

\footnotetext{
${ }^{2}$ Pesquisa multicêntrica coordenada pela Faculdade Enfermagem, realizada em três unidades obstétricas de hospitais de ensino nas cidades de Pelotas/RS; Florianópolis/SC e João Pessoa/PB, financiada pelo Conselho Nacional de Desenvolvimento Científico e Tecnológico (CNPq). Processo 551222/2007-7.

${ }^{3}$ Grupo focal consiste em buscar informações não de um indivíduo, mas de um grupo já existente ou formado especificamente para um período destinado à coleta de dados, que se reúna em torno de um interesse relacionado ao tema da investigação. $\mathrm{O}$ foco não se encontra na análise dos conteúdos manifestos nos grupos, mas sim no discurso que permite inferir o sentido oculto, as representações ideológicas, os valores e os afetos vinculados ao tema investigado.
} 
para as mães e acompanhantes que ficariam coma criança durante a realização do grupo. No primeiro encontro compareceram cinco mães, e no segundo, quatro mães adolescentes. Cabe ressaltar que houve um segundo contato telefônico com as 13 mães para convidá-las a participar do segundo encontro.

No primeiro encontro do grupo focal a pesquisadora no papel de moderadora fez uma breve apresentação da equipe de apoio, foram relatados os objetivos da pesquisa, assim como o porquê da escolha das participantes, após houve a interação entre as participantes em que foi fornecido duas folhas, nas quais deveriam fazer desenhos. $\mathrm{Na}$ primeira folha desenhariam "Eu adolescente grávida”, escreveriam palavras que viessem a sua mente, coisa boas, difíceis, lembranças. Na segunda folha desenhariam "Eu mãe adolescente", escreveriam palavras, sentimentos que viessem a sua memória. Assim, cada participante apresentou o seu desenho e o explicou. Como já havia ocorrido a apresentação do grupo solicitou-se que cada uma falasse um pouco: o que significava gravidez na adolescência; aspectos comuns e discordantes entre as participantes; o que você pensava ao ver uma menina "bem novinha" grávida?

No segundo encontro, foi informado o objetivo desse encontro que seria conhecer motivos que levam as adolescentes a abandonar a escola durante o período de gestação. Por meio de uma técnica de grupo, foi explicado que ficariam jogando os balões até a música parar, uma de cada vez iria estourar o balão e fazer a pergunta para as colegas, sendo a última a responder.

Nos balões havia as seguintes perguntas: Conte como foi sua vida escolar desde os primeiros anos; não se esquecendo de dizer o nome das escolas que freqüentou e qual foi a que você abandonou; seus colegas ficaram sabendo que você estava grávida? O que eles falavam? Qual o nível de ensino dos seus familiares e de seu companheiro e o que eles falam sobre ensino? Quais os motivos que levaram você a abandonar a escola na gravidez?
O que você acha que a escola pode contribuir para o seu futuro e de seu filho? Você recebeu algum apoio da escola quando engravidou? De quem? Você ainda pretende retornar para escola? Quando? O que é necessário para que isso aconteça? Você acha que a escola facilita em alguma coisa para esse retorno?

Ao término de todos os balões, foi lançada uma pergunta ao grupo: Após vocês conhecerem um pouco da história de cada uma, gostaria de saber: O que significa ter saído da escola? Para desenvolver essa etapa foi entregue uma cartolina para o grupo fazer um único desenho representando o que elas achavam da escola e qual o recado que deixariam para as adolescentes com relação ao ensino.

Os dados foram submetidos à análise temática, identificando os núcleos de sentido presentes nas falas dos sujeitos. Para isso foram desenvolvidas três etapas: pré-análise, exploração do material e tratamento dos resultados obtidos e interpretação (6).

O estudo respeitou os princípios éticos de pesquisa envolvendo seres humanos, conforme a Resolução 196/96 do Conselho Nacional de Saúde (7). O projeto foi aprovado pelo Comitê de Ética e Pesquisa da Santa Casa de Misericórdia de Pelotas sob No. 106/2010 Ata 84 de 1 de setembro de 2010. Para manter anonimato dos informantes, as mães adolescentes foram identificadas pelas iniciais do nome e sobrenome acrescidas da idade.

\section{RESULTADOS}

Para melhor compreender os dados deste estudo, buscaram-se subsídios na Teoria das Representações Sociais. As mães adolescentes possuem as suas representações sobre a gravidez na adolescência a partir de seu contexto social, essas representações são mutáveis e dependem de um conjunto de inter-relações também compartilhadas.

As representações são fruto da influência mútua entre indivíduos, unidos em determi- 
nadas culturas que, ao mesmo tempo, constroem e produzem uma história individual e também social (8).

Torna-se relevante inicialmente, apresentar o perfil das mães adolescentes participantes. A idade das mães adolescentes variou entre 15 a 19 anos. Duas eram casadas e três adolescentes, apresentavam união estável com o pai de seu filho. Em relação ao grau de instrução, quatro tinham o ensino fundamental incompleto e uma possuía ensino médio incompleto. A renda familiar variou em torno de um salário mínimo e meio; o pai do bebê e/ou familiares eram os provedores do sustento da família, visto que as mães adolescentes não possuíam ocupação fora do lar.

No presente artigo, os núcleos temáticos encontrados a partir dos grupos focais que emergiram dos relatos da memória das mães adolescentes resultaram em duas categorias: trajetória escolar da adolescente e de seus familiares; e a educação como perspectiva de futuro.

\section{Trajetória escolar da adolescente e de seus familiares}

As representações sociais das adolescentes como sujeitos sociais trazem consigo imagens e hábitos aprendidos, recordações preservadas e categorias culturais, pois para elas os condicionamentos vividos traduzem as suas representações sobre a gravidez e o abandono escolar como um ato de inconsequência que lhes trouxe prejuízos para a construção do seu contexto de vida.

As mães adolescentes deste estudo frequentavam a rede pública de ensino da zona urbana, apresentavam histórias semelhantes de pertencer a família de baixa renda e baixa escolaridade e uma trajetória escolar de reprovação de um ou mais anos, reproduzindo uma distorção série/idade.

Assim, representavam a sua trajetória escolar com dificuldades para acompanhar o projeto pedagógico do ensino ao longo dos anos escolares, e no transcorrer da gravidez as manifestações dificultaram a sua permanência na escola, fazendo com que elas optassem por abandonar os estudos, o que pode ser evidenciado nas falas a seguir:

Eu sempre fui ruim em matemática, mas a trancos e barrancos eu sempre passei.

Na sexta série e continuei estudando, mas nunca parei (...), achava que eu não ia passar, mas estudei bastante e consegui. Na oitava série troquei de escola, não passei no primeiro ano porque eu entrei na metade; no segundo ano, estudei e rodei, e quando eu fui estudar à noite eu engravidei e parei (KSB 18).

Estudei sempre na mesma escola, quando eu estudava era bom, até a quinta série eu passei sempre, fui péssima em matemática, tinha que tirar 6, eu tirava 6 cravadinho. Repeti a sexta e a sétima série (risos). Quando passei para a oitava série parei, mas eu tinha chance de passar, mas como eu estava ruim (sintomas da gravidez) eu parei (JLS 17).

Observa-se nas falas dessas mães adolescentes que, mesmo com dificuldades escolares e as reprovações frequentes, elas permaneciam na rede escolar, porém a gestação foi o ponto-chave para a evasão escolar. Com a chegada do recém nascido, a família que provém o sustento, não dispunha de condições financeiras, emocionais e de tempo para apoiar a adolescente no cuidado com o filho, o que acaba por agravar a evasão escolar.

As mães adolescentes relataram que sua família, pais, irmãos e seu companheiro possuíam, em sua maioria, baixa escolaridade. A história da educação rural com ensino de primeira à quarta série do ensino fundamental foi evidenciada e ainda é comum nos dias atuais. Narraram histórias semelhantes às suas:

A minha mãe estudou até a terceira série, o meu pai acho que foi até a primeira ou segunda, não sei, o meu irmão de 13 anos está na sexta série, meu marido parou no $1^{\circ}$ ano do segundo grau. Ele e minha mãe querem voltar a estudar, só o meu pai que não (JLS 17). 
A minha mãe estudou até a terceira série, porque ela morava para fora (zona rural), ela chegou a fazer a quarta, mas nunca terminou. Naquele tempo os pais não priorizavam muito os estudos, o meu pai estudou também até a terceira pelo mesmo fato, a minha irmã estudou até a sexta porque ela ficou grávida e quis parar de estudar, ela já tentou várias vezes voltar, mas nunca conseguiu. Meu irmão estudo u até a quinta série e parou. E o pai do meu filho parou de estudar no $1^{\circ}$ ano do ensino médio, mas por minha culpa (sintomas da gravidez), porque ele gosta de estudar, ele é bem inteligente, a mãe dele é formada, todos da família dele são formados (nivel superior) (KSB 18).

\section{A educação como perspectiva de futuro}

As respondentes expõem que estão cientes das dificuldades que enfrentarão no mercado de trabalho em conseguir uma remuneração melhor se não manterem-se na escola. A adolescente MMP 19 traduz o seu pensamento com relação ao ensino com a seguinte fala:

Quanto mais eu tiver um ensino completo fica mais fácil de eu pegar um serviço melhor (MMP 19).

As adolescentes desta pesquisa reproduziram as representações da sociedade, ao afirmarem que o estudo favorece melhores condições de vida, pois valorizavam aquisição de bens de consumo e ancoravam a educação na idéia de melhor emprego, com melhor salário e consumo de produtos mais caros para seus filhos.

Eu acredito que ter estudo é bom para conseguir um serviço (APXC 15).

Melhora, porque eu vou ganhar um salário methor, vou dar as coisas mais caras para o meu filho, vou dar o que eu quero dar e, se eu não tiver estudo, eu não vou ter condições (MMP 19).

As adolescentes ao mesmo tempo relacionaram que o aumento do seu nível educa- cional favorecia o seu desenvolvimento intelectual e facilitaria a educação de seus filhos. Nenhuma relacionou a educação como uma aspiração futura para a construção de um mundo melhor. No entanto, reconheceram a importância da educação, e justificaram o valor do estudo como forma de oferecer melhores condições de vida para os filhos.

Acredito que melhora financeiramente, e também na educação, eu vou ter mais conhecimento, não vou ser tão tapada para responder todas aquelas perguntas que criança faz (KSB 18). Também acho que é importante ter estudo para arrumar um serviço melhor, para dar uma educação melhor para os filhos, pois sem estudo hoje em dia a gente não consegue nada, então eu acho que é importante (JLS 17).

A seguir, as jovens MMP 19 e KSB 18 demonstram a dificuldade em retornar ao sistema escolar, mas ao mesmo tempo representa a necessidade das jovens mães brasileiras, mencionando um projeto para nossos governantes.

É uma coisa muito difícil de acontecer ter uma creche na escola, até seria bom se tivesse um projeto desses, mas eu creio que é muito difícil, mas acho que muita gente ia voltar a estudar, porque ter o filho é complicado, para estudar, para trabalhar, para tudo que é coisa (MMP 19).

Para mim foi burrice eu ter saído da escola, poderia ter continuado estudando, já estaria mais adiantada, seria mais fácil; mas querer todo mundo quer, agora vamos ver se eu vou conseguir conciliar casa, marido, filho e tudo isso (KSB 18).

\section{DISCUSSÃO E CONCLUSÃO}

No que tange a trajetória escolar das adolescentes e de seus familiares, observa-se que, apesar de construir sua representação social 
sobre a gravidez como algo positivo e socialmente valorizado, pois ganha status diferenciado no núcleo familiar, a adolescente se depara com novas dificuldades no papel de mãe, não encontrando em seu contexto de vida a educação como uma representação que lhe possibilite romper com o ciclo da pobreza.

Então, o profissional da saúde, em especial o enfermeiro, assim como os profissionais das escolas, deveriam apreender as representações das adolescentes sobre as manifestações da gestação tanto físicas quanto psicológicas. Isso pode contribuir para o reconhecimento dos fatores que dificultam a permanência na escola, bem como fortalecer novas representações a cerca da educação a fim de promover o empoderamento social das mães adolescentes.

Porém, em nossa realidade observa-se que tanto as escolas como os serviços de saúde não estão preparados para enfrentar esse problema, pois não disponibilizam apoio para esta população a fim de encorajá-las e conscientizá-las sobre a importância da educação para o crescimento pessoal e profissional. Esse despreparo pode ser evidenciado, por exemplo, nas consultas de pré-natal, nas quais os profissionais de saúde mantêm uma visão curativa, procurando somente o bemestar do binômio mãe/feto, sem percebê-las na sua individualidade. É oportuno que nas consultas de pré-natal o profissional da saúde estimule a permanência das mães adolescentes no sistema escolar, pois com ascensão da escolaridade a taxa de reprodução na adolescência poderá diminuir, assim também como o cuidado como recém-nascido poderá ser mais qualificado.

Nesse sentido, o pensamento acima, sobre a importância do incentivo à permanência na escola, foi demonstrado em um estudo em 2008, envolvendo 50 gestantes adolescentes que tinham frequentes reuniões com um grupo multiprofissional durante toda a gravidez. O estudo mostrou que, após o acompanhamento, a taxa de retorno à escola foi de
$24 \%$ e essas adolescentes tinham uma rede social de apoio familiar e do pai da criança, sendo que $48 \%$ estavam empregadas. Foram observados, ainda, maior tempo de amamentação, maior cobertura vacinal e a média de escolaridade superior à média nacional, sendo possível considerar que o programa promoveu retorno à educação (9).

O estudo multicêntrico com jovens sobre Sexualidade e Reprodução no Brasil indica que os que possuíam menor renda per capi$\mathrm{ta}$, negros, e aqueles cujas mães tinham menor escolaridade possuíam trajetória escolar irregular, confirmando a generalização de marcantes desigualdades sociais no Brasil. O estudo destacou que a gravidez na adolescência é considerada responsável pelo abandono escolar e, consequentemente, pela perda de melhores oportunidades de emprego (1).

Pode-se observar ainda na trajetória escolar das mães adolescentes que elas reproduzem a história de desistência escolar de seus familiares, caracterizando uma forma de perpetuação do ciclo da baixa escolaridade, condições socioeconômicas desfavoráveis e vulnerabilidade. $\mathrm{Na}$ adolescência os jovens têm a ansiedade de viver intensamente, o que leva à falta de espaço para reflexão ou julgamentos. Dessa forma, ficam mais vulneráveis ao uso de drogas, gravidez na adolescência, AIDS e outras doenças sexualmente transmissíveis, que podem comprometer o projeto de vida dos adolescentes (10).

É importante rever as questões de gênero, pois as jovens ancoram muitas vezes suas decisões nas representações sociais vividas em nossa sociedade de que os cuidados com os filhos são de responsabilidade exclusiva das mães e o papel do homem é o de provedor financeiro da família.

Neste sentido, o estudo qualitativo e quantitativo desenvolvido em cinco províncias e zonas metropolitanas da Argentina com meninos e meninas adolescentes a fim de investigar o abandono escolar, gravidez na adolescência e pobreza, vem confirmar as diferenças de gênero, quando afirma que a gra- 
videz na adolescência com o fator de evasão escolar tem relação diferenciada quanto ao gênero (11). A jovem mãe justifica seu afastamento da escola para assumir a responsabilidade com os serviços domésticos, o cuidado e o sustento do filho; enquanto que o jovem pai justifica seu desligamento da escola para busca de rendimentos próprios por intermédio do trabalho, em função dos anseios por um projeto de autonomia e expectativas de consumo (11).

Ao descrever as representações sociais das jovens mães quanto à sua trajetória escolar e de seus familiares, é relevante apontar que o sistema de ensino, apesar das modificações curriculares, ao longo dos anos, ainda parece incapaz de conscientizar seus alunos da importância da educação. Isso pode ocorrer porque a mesma ainda não é percebida como o ponto crucial para o rompimento do círculo vicioso da pobreza.

Quanto a educação como perspectiva de futuro, pode-se dizer que a representação social das adolescentes quanto à educação provém do universo vivido, a partir das trocas e práticas do contexto por elas experienciado. Para muitas crianças e jovens brasileiros impõe-se uma realidade inconciliável com a sua manutenção na escola, criando um ciclo de difícil adaptação: a necessidade de abandonar a escola para trabalhar e a posterior verificação de que ficou com baixa escolaridade. Dessa forma, o jovem encontrará significativas dificuldades em conseguir melhor exposições profissionais, mantendo por vezes gerações aprisionadas ao trabalho informal e aos subempregos (9).

A gravidez precoce funciona como fator de exclusão social, diminuindo as possibilidades de melhorar as condições de vida. Entretanto, as adolescentes grávidas de baixa escolaridade permanecem cumprindo o seu papel social, porém as limitações que o mundo moderno impõe a quem não tem estudo restringem e comprometem o crescimento individual e social dessas jovens (12). Assim, um projeto que atendesse às necessidades das mães adolescentes, como, por exemplo, a inclusão de creche nas escolas, poderia subsidiar sua permanência no meio escolar e, com isso, promover a sua cidadania e o empoderamento social.

Em um estudo de revisão de literatura sobre gravidez na adolescência e evasão escolar, o sistema educativo dos alunos, suas aspirações na escola e as políticas que afetam a sua educação, observou que embora as adolescentes tenham uma série de desvantagens educativas e sociais com a maternidade, muitas reiniciam a escola para melhorar suas oportunidades futuras (13).

Neste estudo, as adolescentes reconheceram a importância da educação, no entanto, ancoravam-se na sociedade capitalista que valoriza a educação como fonte de ascensão econômica, ao invés de perceber o verdadeiro valor de empoderamento social que pode ser adquirido por meio da inclusão escolar. Impõem-se, ainda, como dificuldades nesse processo, conciliar as responsabilidades adquiridas em ser mãe adolescente de baixa renda, que precisa cuidar do filho, trabalhar para melhorar as condições familiares e voltar a estudar.

Nesse cenário, a enfermagem precisa estar presente na vida dos adolescentes não apenas com um olhar centrado em ações biomédicas, mas desenvolvendo programas com enfoque na prevenção e promoção da saúde. Pensar em saúde é uma tarefa de diferentes setores da sociedade, porém a enfermagem, ao unir-se às escolas, estimularia a permanência e/ou retorno da mãe adolescente ao sistema escolar com o meio de empoderamento social, estimulando os adolescentes a criar novas representações sociais ancoradas em suas conquistas através da ascensão escolar.

Com o presente estudo, foi possível apreender as representações sociais das mães adolescentes acerca da importância da educação, por meio da sua trajetória escolar e de suas perspectivas para o futuro.

A construção das representações sociais 
sobre a importância da educação para mães adolescentes edificou-se em pensamentos ancorados no sistema socioeconômico vigente, no qual a educação está atrelada à mão de obra qualificada e, consequentemente, a melhores salários e oportunidades de trabalho e ascensão social.

As jovens mães, por meio de uma trajetória escolar marcada por desajuste idade/série, reprovações e abandonos, apontaram o processo escolar com o importante para o futuro, principalmente para o de seu filho, porém reconheceram as dificuldades para o retorno e permanência na escola.

As adolescentes deste estudo, em seu processo de maternagem, apoiaram-se nas alterações físicas e psíquicas da gravidez e na responsabilidade de cuidar de seus filhos para justificarem o abandono escolar e o distanciamento da decisão de um retorno aos estudos.

Entretanto, as mães adolescentes apontaram que ainda faltam políticas públicas no nosso país que viabilizem a permanência das adolescentes grávidas no sistema educacional. Por essa razão, novos estudos precisam ser desenvolvidos com o intuito de apontar caminhos para inserção das jovens mães no sistema escolar.

Além disso, ao evidenciar os processos de ancoragem e objetivação das mães adolescentes no contexto escolar, o estudo também contribuirá para a identificação dos ambientes e fatores sociais que compõem as representações sociais das adolescentes acerca da evasão escolar na maternidade.

\section{REFERÊNCIAS}

1. Almeida MC, Aquino EM. Adolescent pregnancy and completion of basic education: a study of young people in three state capital cities in Brazil. Cad Saude Publica. 2011; 27(12): 2386-2400.

2. Padilha MA, Hypolito ÁM, Soares MC,
Könzgen S, Nunes M, Machado A, et al. [Teen mothers and school dropout: a systematized review]. Revista de enfermagem UFPE on line. 2011; 5(6): 15341540. Portuguese.

3. Moscovici S. Representações Sociais: investigações em psicologia social. 5.ed. Petrópolis: Vozes; 2007.

4. Cromack LM, Bursztyn I, Tura LF. O olhar do adolescente sobre saúde: um estudo de representações sociais. Cien Saude Colet. 2009; 14(2): 627-634.

5. Silva LA, Nakano AM, Gomes FA, Stefanello J. Significados atribuídos por puérperas adolescentes à maternidade: autocuidado e cuidado com o bebê. Texto Contexto Enferm. 2009; 18(1): 48-56.

6. Minayo MC. O desafio do conhecimento: pesquisa qualitativa em saúde. São Paulo: Hucitec; 2010. 407 p.

7. Ministério da Saúde (BR). Conselho Nacional de Saúde. Diretrizes e normas regulamentadoras de pesquisa envolvendo seres humanos. Resolução No 196 de 10 de outubro de 1996. Brasília (DF): Ministério da Saúde; 1996.

8. Jodelet D. Representações sociais: um domínio em expansão. En: Jodelet D, organizador. As representações sociais. Rio de Janeiro: Ed. UERJ; 2001.

9. Oliveira M. Representações sociais e sociedades: a contribuição de Serge Moscovici. Rev. bras. Ci. Soc. 2004; 19(55): 180186.

10. Fonseca AD, Gomes VL, Teixeira KC. Percepção de adolescentes sobre uma ação educativa em orientação sexual realizada por acadêmicos(as) de enfermagem. Esc. Anna Nery. 2010; 14(2): 330-337.

11. Gogna M, Binstock G, Fernández S, Ibarlucía I, Zamberlin N. Adolescent pregnancy in Argentina: evidence-based recommendations for public policies. Reprod Health Matters. 2008; 16(31): 192201.

12. Souza AX, Nobrega SM, Coutinho MP. Representações sociais de adolescen- 
tes grávidas sobre a gravidez na adoles- 13. Silveira RE, Santos AS. Pregnancy in adocência. Psicol Soc (Bologna). 2012;3(24): lescence and school dropout: an integra588-596. tive Literature review. REAS. 2013; 2(1): 89-98. 